\title{
Criteria for diagnosis of temporary gluten intolerance
}

\author{
A. S. McNEISH, C. J. ROLLES, and L. J. H. ARTHUR \\ From the Institute of Child Health, University of Birmingham, and Derbyshire Children's Hospital, Derby
}

\begin{abstract}
McNeish, A. S., Rolles, C. J., and Arthur, L. J. H. (1976). Archives of Disease in Childhood, 51, 275. Criteria for diagnosis of temporary gluten intolerance. Strict criteria for the diagnosis of temporary gluten intolerance are formulated in the light of the case of an 8-week-old infant with severe diarrhoea and failure to thrive, who recovered on an elimination diet that was gluten-free. 8 weeks later an oral challenge with $2.5 \mathrm{~g}$ twice daily of powdered gluten for one day produced diarrhoea, weight loss, and impaired xylose absorption. Gluten was successfully reintroduced into the diet 9 months later without incident. Jejunal histology remains normal after 26 months of a daily diet that contains 5 to $10 \mathrm{~g}$ gluten.
\end{abstract}

The possible existence of temporary gluten intoleranc: in children is still a contentious subject. In early descriptions (Dicke, 1952; Visakorpi and Immonen, 1967) diagnosis was based upon serial clinical observations and biochemical tests of malabsorption when the child was placed on a gluten-free diet, and then later after gluten reintroduction. Jejunal histology was not studied. The child described by Walker-Smith (1970) had serial jejunal biopsies to confirm recovery, but even in this case the evidence was not conclusive.

The general argument used in the above cases is illustrated in Fig. 1. An ill child improves when gluten is removed from the diet; months or years later gluten is reintroduced into the diet without ill-effects; previous gluten intolerance is inferred. However, it is obvious that improvement may have been coincidentally associated with a dietary change. At no time was gluten sensitivity proven. Mini-

Received 4 July 1975.

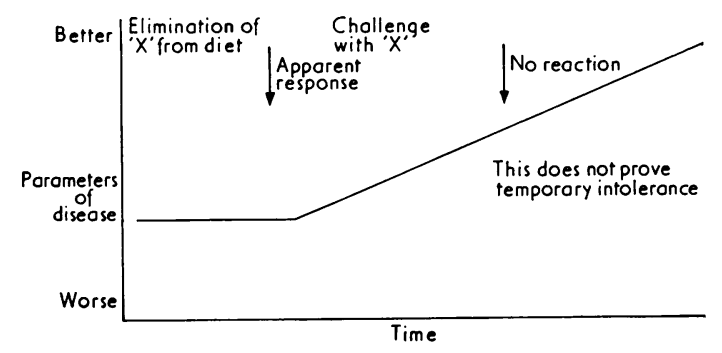

Fig. 1.-Commonly used criteria of temporary food intolerance. mum criteria for proving temporary gluten intolerance are illustrated in Fig. 2. A positive response to a gluten challenge after the initial recovery confirms gluten sensitivity, and a later negative challenge indicates that the intolerance was temporary. We report a child who fulfills these stricter criteria.

\section{Case report}

A boy, born on 21 October 1971 weighing $4.2 \mathrm{~kg}$, was fed from birth with full-cream cow's milk, and wheat cereals were added when he was 3 weeks old. From the age of one week he passed 4-7 semiformed stools each day, which became more loose between 4 and 8 weeks. He was admitted to hospital in Derby aged 8 weeks weighing $4.0 \mathrm{~kg}$, moderately wasted, and slightly dehydrated. The stools were watery and contained $1-2 \%$ reducing substances (Clinitest). Further findings included negative stool and blood cultures; no fat globules, ova, cysts, or occult blood in stools; normal values for serum proteins, sweat electrolytes, urinary vanilylmandelic acid (VMA), serum $\beta$-lipoproteins;

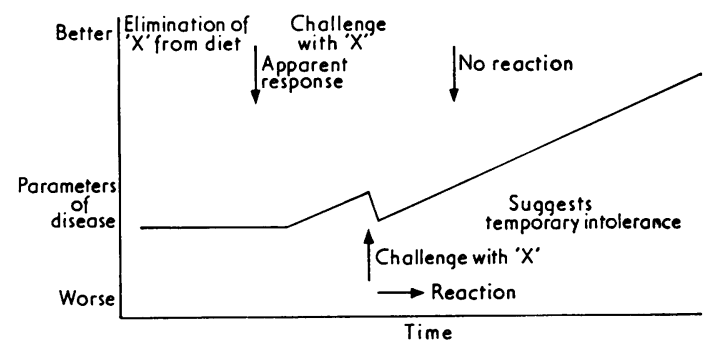

FIG. 2.-Stricter criteria of temporary food intolerance, used in present case. 


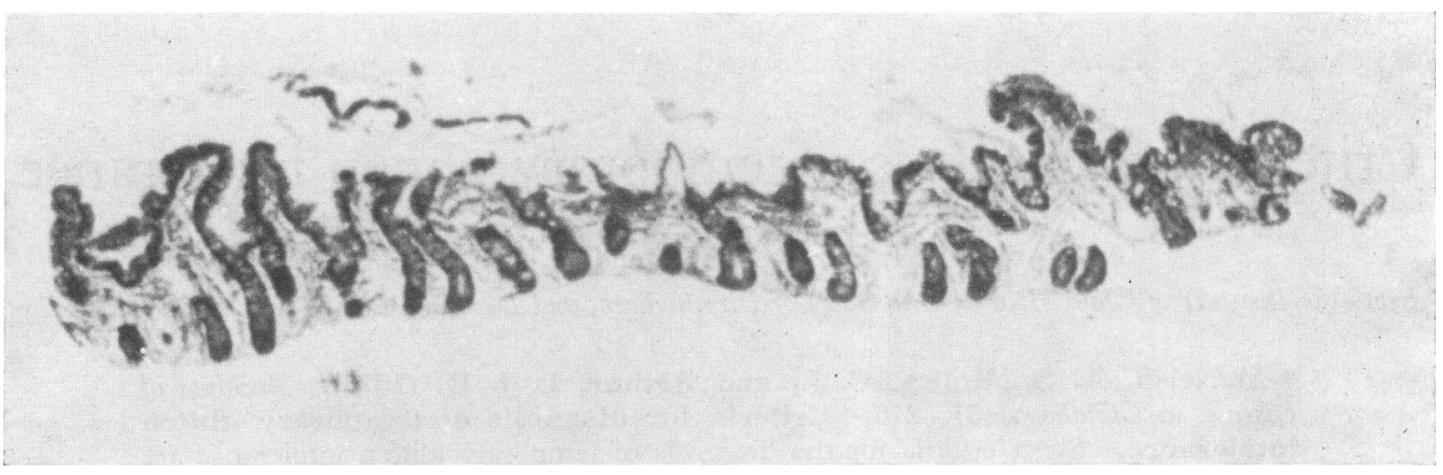

FIG. 3.-Initial jejunal biopsy of patient when aged 8 weeks. $(\times 60$.

normal barium examination of upper and lower gastrointestinal tract. Jejunal biopsy (Fig. 3) showed stunting of villi, epithelial irregularity, and increased cellularity of the lamina propria.

His clinical course is summarized in Fig. 4. For 6 weeks he was fed successively with Low-Lactose Food (Cow \& Gate), expressed breast milk, and Galactomin 17 (Cow \& Gate) with no improvement. On three occasions he collapsed with profuse diarrhoea, requiring steroids and intravenous fluids. For a further 3 weeks he was maintained on total intravenous feeding and then was transferred gradually to a soy-protein formula (Velactin, Wander) with vitamin supplements. The stools were now more formed and he gained weight. Further investigations at Birmingham showed $\mathrm{Hb} 12 \mathrm{~g} / \mathrm{dl}$; faecal fat $1.3 \mathrm{~g} / \mathrm{d}$; one-hour blood d-xylose $28 \mathrm{mg}$ / $100 \mathrm{ml}$ (normal $>20 \mathrm{mg} / 100 \mathrm{ml}$ after $5 \mathrm{~g}$ oral dose). Serum immunoglobulins showed selective IgA deficiency.

Serial oral challenges with lactose $(2 \mathrm{~g} / \mathrm{kg})$ and cow's milk $(20-100 \mathrm{ml})$ produced no symptoms. Introduction of powdered gluten in a dose of $2.5 \mathrm{~g}$ twice daily for one day induced vomiting after 4 hours. Five very loose stools were passed in the next 24 hours and the weight fell by $600 \mathrm{~g}$. A one-hour blood D-xylose test performed immediately before the gluten challenge

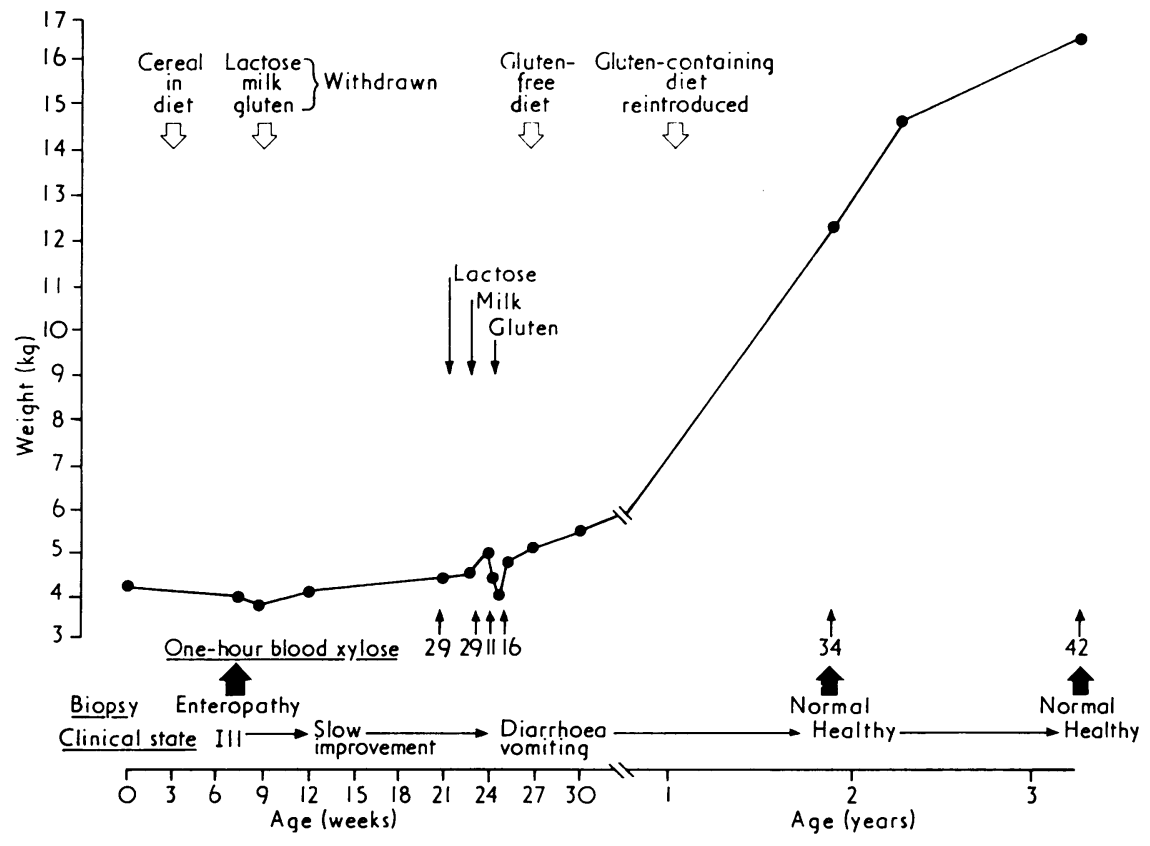

FIG. 4.-Summary of clinical course. 
gave a normal result of $29 \mathrm{mg} / 100 \mathrm{ml}$. The next day this had fallen to $11 \mathrm{mg} / 100 \mathrm{ml}$, but rose to $16 \mathrm{mg} /$ $100 \mathrm{ml}$ one day later.

He again progressed satisfactorily on a gluten-free, lactose- and cow's milk-containing diet. 9 months later his mother reintroduced gluten-containing foods without ill effects. For the next 2 years he ate an estimated 5-10 $\mathrm{g}$ of gluten every day and continued to thrive. Serial xylose absorption tests and faecal fats have remained normal. Jejunal biopsies obtained after 9 months and 26 months of gluten ingestion are normal (Figs. 5 and 6).

\section{Discussion}

We believe that the criteria in Fig. 2 must be met in order to support the diagnosis of temporary gluten (or other dietary) intolerance. An improvement apparently caused by a dietary elimination may be coincidental, particularly because dietary trials are usually carried out in hospital where other environmental factors may be controlled or altered, or other treatments given.

The demonstration of a positive gluten challenge in this case, later followed by the ability to tolerate gluten is substantial evidence for a true temporary gluten sensitivity. The positive response to gluten was indicated by the onset of obvious clinical symptoms, and by a depression of $\mathrm{D}$-xylose absorption. We have already shown that gluten causes a depression of $\mathrm{D}$-xylose absoprtion in treated coeliac children (Rolles, Anderson, and McNeish, 1975). The fall in the one-hour blood D-xylose test (Rolles, et al., 1973) from a normal value of $29 \mathrm{mg} / 100 \mathrm{ml}$ to $11 \mathrm{mg} / 100 \mathrm{ml}$ one day later is characteristic of a positive response.

We did not attempt to show a histological change in the jejunal mucosa after challenge because the speed of the reaction to gluten was probably too quick to have produced an obvious alteration in the villous architecture. Perhaps in future cases it may be possible to show histologically a local immune reaction, such as has recently been shown to occur in the hours after milk challenge in cow's milk allergy (Shiner, Ballard, and Smith, 1975).

The reaction to gluten in our case was fairly pronounced. We now consider that it is safer to delay any gluten challenge until the child is more than one year old (Rolles, et al., 1975), even though it is likely that by that age many states of temporary dietary intolerance will have recovered and formal proof of their existence will be harder to find.

We do not think that this child has coeliac disease. He has eaten a diet for 2 years that

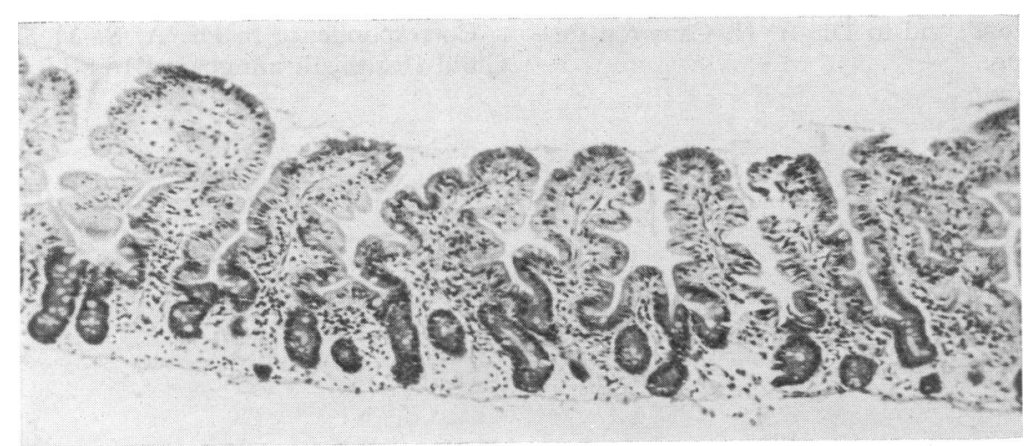

Fig. 5.-Jejunal biopsy of patient, aged 2 years, after 9 months on gluten-containing diet.

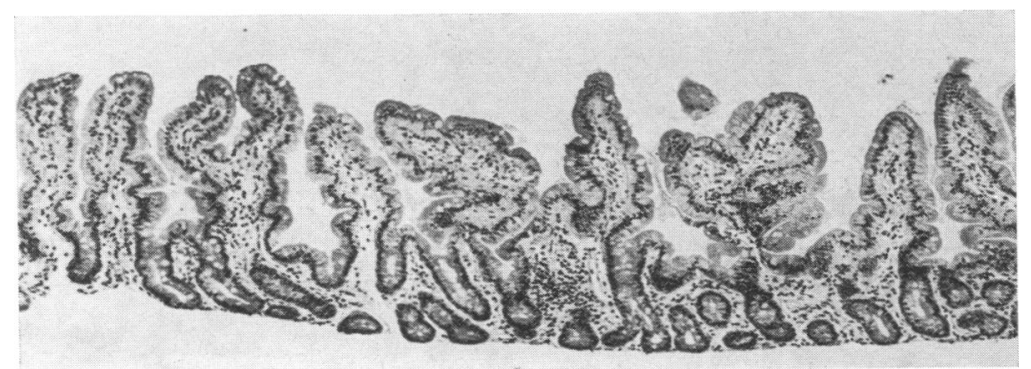

FIG. 6.-Jejunal biopsy of patient, aged $3 \frac{1}{2}$ years, after 26 months on gluten-ccntaining diet. $(\times 120$. 
contained 5-10 $\mathrm{g}$ or more of gluten each day, yet he is symptom free and growing normally, and his jejunal mucosa remains normal (Figs. 5 and 6). The timing of a relapse in coeliac disease is partly dependent on the dose of ingested gluten (McNeish, et al., 1974). His high gluten intake would surely have caused at least a histological relapse within 2 years if he had coeliac disease.

The cause of temporary gluten intolerance is unknown. It may have much in common with the cow's milk protein intolerance that can follow gastroenteritis (Visakorpi, 1974), and may have as its basis a temporary increase in absorption from the gut of protein macromolecules (Walker, Isselbacher, and Bloch, 1972). In our case selective IgA deficiency may have been important in allowing abnormal absorption of dietary gluten. It is known that such individuals may have high serum antibody titres against a variety of food antigens (Buckley and Dees, 1969). The earliest bowel symptoms in this child could have been caused partly by milk protein intolerance, though no evidence was found several months later. It also remains to be shown whether the presumed immunological mechanisms in this case are in any way similar to those that operate in coeliac disease.

We are grateful to Professor Charlotte $M$. Anderson for helpful discussions, and to Dr. A. H. Cameron for histological reporting.
REFERENCES

Buckley, R. H., and Dees, S. C. (1969). Correlation of milk precipitins with IgA deficiency. New England fournal of Medicine, 281, 465.

Dicke, W. K. (1952). De subacute, chronische en recidiverende darmstoornis van de kleuter. Nederlandsch Tijdschrift voor Geneeskunde, 86, 860.

McNeish, A. S., Rolles, C. J., Nelson, R., Kyaw-Myint, T. O. Mackintosh, P., and Williams, A. F. (1974). Factors affecting the differing racial incidence of coeliac disease. Coeliac Disease: Proceedings of the Second International Coeliac Symposium. Ed. by W. Th. J. M. Hekkens and A. S. Pena. Stenfert-Kroese, Leiden.

Rolles, C. J., Anderson, C. M., and McNeish, A. S. (1975). Confirming the persistence of gluten intolerance in children diagnosed as having coeliac disease in infancy: usefulness of the one-hour blood xylose test. Archives of Disease in Childhood, 50, 259.

Rolles, C. J., Kendall, M. J., Nutter, S., and Anderson, C. M. (1973). One-hour blood-xylose screening-test for coeliac disease in infants and young children. Lancet, 2, 1043.

Shiner, M., Ballard, J., and Smith, M. E. (1975). The small intestinal mucosa in cows milk allergy. Lancet, $1,136$.

Visakorpi, J. K. (1974). Definition of coeliac disease in children. Coeliac Disease: Proceedings of the Second International Coeliac Symposium. Ed. by W. Th. J. M. Hekkens and A. S. Pena. Stenfert-Kroese, Leiden.

Visakorpi, J. K., and Immonen, P. (1967). Intolerance to cow's milk and wheat gluten in the primary malabsorption syndrome in infancy. Acta Paediatrica Scandinavica, 56, 49.

Walker, W. A., Isselbacher, K. J., and Bloch, K. J. (1972). Intestinal uptake of macromolecules: effect of oral immunization. Science, 177, 608.

Walker-Smith, J. (1970). Transient gluten intolerance. Archives of Disease in Childhood, 45, 523.

Correspondence to Dr. A. S. McNeish, Institute of Child Health, Birmingham B16 8ET. 